\title{
DESINDUSTRIALIZAÇÃO NO BRASIL E ANÁLISE REGIONAL: EVIDÊNCIAS EMPÍRICAS DA CONFIGURAÇÃO DESIGUAL
}

\section{DEINDUSTRIALIZATION IN BRAZIL AND REGIONAL ANALYSIS: EMPIRICAL EVIDENCE OF THE UNEQUAL CONFIGURATION}

\author{
Érica Priscilla Carvalho de Lima MACHADO ${ }^{1}$ \\ Elaine Carvalho DE LIMA ${ }^{2}$
}

\begin{abstract}
Resumo: A desindustrialização é uma reversão do crescimento e peso da atividade industrial na dinâmica econômica. Tal conceito pode ser compreendido mediante a observação da perda da participação do emprego industrial e do valor adicionado da indústria em relação ao emprego total e PIB, respectivamente. Os dados da participação do emprego industrial e do valor adicionado, no Brasil, apresentaram uma tendência declinante ao longo das duas últimas décadas. Com efeito, as evidências empíricas mostram que há indubitavelmente uma redução da participação da indústria na dinâmica da economia brasileira. No entanto, as elevadas disparidades regionais existentes no território nacional corroboram uma configuração heterogênea do processo de desindustrialização. $O$ presente artigo teve por objetivo analisar o processo de desindustrialização mediante a configuração do emprego nas diferentes regiões brasileiras. Os principais resultados reiteraram a persistência de elevada diferenciação industrial entre as regiões, tendo em vista que não há um padrão homogêneo de distribuição espacial. Ademais, intensifica-se a importância de políticas que priorizem uma maior desconcentração espacial da atividade, especialmente na diminuição dos gargalos de infraestrutura existentes nas regiões que impedem uma maior competitividade das áreas mais atrasadas.
\end{abstract}

Palavras-Chaves: Desindustrialização; Economia regional; Heterogeneidade industrial.

\begin{abstract}
The deindustrialization is a reversal of growth and weight of industrial activity in economic dynamics. Such a concept can be understood by observing the loss of industrial jobs and participation in value added of industry in relation to total employment and GDP, respectively. The data of industrial employment participation and value added, in Brazil, showed a declining trend over the last two decades. Indeed, the empirical evidence shows that there is undoubtedly a reduction in industry participation in the dynamic brazilian economy. However, the high regional disparities existing in the country support a heterogeneous configuration in the process of deindustrialisation. This article aimed to analyze the process of deindustrialisation by employment setting in the different Brazilian regions. The main results reiterated the persistence of high industrial differentiation between the regions, considering that there is a homogeneous spatial distribution pattern. Moreover, intensifies the importance of policies that prioritize a greater devolution of space activity, especially in the reduction of the existing infrastructure bottlenecks which prevent regions a greater competitiveness of lagging areas.
\end{abstract}

Keywords: Deindustrialisation; Regional economy; Industrial heterogeneity.

\footnotetext{
${ }^{1}$ Doutora em Economia pela Universidade Federal de Uberlândia. Professora da Universidade Federal do Rio Grande do Norte. E-mail: ericapcl1@gmail.com

${ }^{2}$ Doutora em Economia pela Universidade Federal de Uberlândia. Professora do Instituto Federal do Amazonas.

E-mail: elaine.lima@ifam.edu.br
} 


\section{Introdução}

A conceituação de desenvolvimento econômico envolve um processo sustentado de crescimento, que combina mudança da estrutura produtiva com distribuição de renda. A literatura acerca do desenvolvimento econômico ressalta a emergência de uma gradual alteração da estrutura econômica, a qual passaria de um estágio agrário com tendência de atenuação em detrimento do crescimento industrial e, posteriormente, centrada no setor terciário.

Ao analisar o padrão de desenvolvimento brasileiro, Filgueiras (2012) explicita dois planos de debate teórico. Enquanto que o primeiro trata do atual desempenho da economia nacional, o segundo retrata os condicionantes que influenciarão a trajetória futura da economia, de modo favorável ou não à superação do subdesenvolvimento. Diante das diferentes interpretações que emergem, o autor supracitado identifica uma vertente póskeynesiana e marxista que visa contribuir com a discussão acerca da estrutura produtiva e da pauta exportadora do país.

O padrão de desenvolvimento, segundo essa visão teórica, centra-se no debate da especialização produtiva regressiva e de uma acentuação da vulnerabilidade externa. A explicação para isso reside tanto em condições relacionadas ao cenário internacional, como pelas políticas macroeconômicas adotadas. Desta forma, o autor salienta que, concomitantemente, verifica-se a ocorrência do processo de desindustrialização, da reprimarização e da especialização regressiva.

Autores como Oreiro e Feijó (2010) e Sarti e Hiratuka (2010), via de regra, discutem elementos teóricos sobre o processo de mudança estrutural brasileiro, no sentido de mostrar evidências acerca da perda da relevância do setor industrial para o crescimento econômico do país. Desta forma, os autores ratificam a ocorrência da desindustrialização brasileira e problematizam tal processo devido seu caráter "precoce".

O processo de desindustrialização é caracterizado, sobretudo, pela perda da participação da indústria no Produto Interno Bruto (PIB) e do emprego industrial no emprego total (ROWTHORN; RAMASWANY, 1999; TREGENNA, 2009). Uma crítica que surge, em especial quando se analisa o caso brasileiro, é a não incorporação de setores industriais mais avançados e serviços mais qualificados, apoiando a hipótese de precocidade da desindustrialização nacional. 
Isso posto, a desindustrialização é uma reversão do crescimento e peso da atividade industrial na dinâmica econômica, entretanto não significa, necessariamente, um fenômeno danoso, pois é crucial saber em quais circunstâncias esse processo ocorre. Nos países ricos verifica-se que a redução da participação da indústria ocorre pari passu a utilização de produtos que são intensivos em tecnologia e ao crescimento de um setor de serviços mais diversificado.

No caso brasileiro, particularmente, a conjuntura da ocorrência da desindustrialização suscita elementos que ameaçam o crescimento econômico, tendo em vista que o país não atravessou fases anteriores de desenvolvimento industrial que garantisse, ao setor, níveis de competitividade e produtividade compatíveis com o cenário internacional.

Segundo dados da Relação Anual de Informações Sociais (RAIS), o peso do emprego formal da indústria de transformação em relação ao emprego total, no Brasil, foi de $15,74 \%$ em 2015, ao passo que esse mesmo indicador atingiu aproximadamente 21\%, em 1995. No que diz respeito ao valor adicionado da indústria de transformação no PIB verifica-se também a redução da participação, visto que representou $12 \%$ em 2014, enquanto que representava $17,8 \%$ em 2000.

Com efeito, as evidências empíricas mostram que há indubitavelmente uma redução da participação da indústria na dinâmica da economia brasileira. No entanto, as elevadas disparidades regionais existentes no território nacional corroboram uma configuração heterogênea do processo de desindustrialização.

Assim, o objetivo do artigo é analisar a desindustrialização brasileira mediante a configuração da indústria nas regiões, nas duas últimas décadas. Justifica-se a realização deste estudo, sem dúvida, pela existência de disparidades espaços-territoriais que se manifestam em um elevado nível de heterogeneidade regional, em especial no setor industrial.

Portanto, este ensaio se encontra dividido em mais quatro seções incrementalmente a introdução. A seguir, faz-se uma breve revisão sobre as interpretações teóricas que tratam a desindustrialização; na sequência, realiza-se a exposição dos procedimentos metodológicos; posteriormente, discutem-se os principais resultados alcançados no trabalho, reservando ao último item a apresentação de algumas considerações finais. 


\section{Discussão conceitual acerca da desindustrialização}

A relevância do desenvolvimento industrial se justifica pelo setor estar atrelado ao processo de geração e difusão de inovações, bem como ser central para conduzir à transformação da estrutura produtiva. Com efeito, a política industrial passa a ser vista como uma política de desenvolvimento específica, visto que o desenvolvimento é condicionado pela mudança estrutural, ampliação da demanda efetiva e transformação das instituições (GADELHA, 1999).

Uma discussão recorrente na literatura sobre a atividade industrial é a ocorrência ou não de um processo de desindustrialização no Brasil e seus impactos na dinâmica da economia nacional. No entanto, a desindustrialização não se traduz, necessariamente, em um fenômeno danoso, pois é crucial saber em quais circunstâncias ela ocorre.

No final dos anos 1990, o conceito de desindustrialização foi definido por Rowthorn e Ramaswany (1999) caracterizado por uma perda persistente da participação do emprego industrial no emprego total de um país ou região. Tregenna (2009) redefiniu e ampliou o escopo conceitual de desindustrialização, definido como sendo uma situação na qual tanto o emprego industrial como o valor agregado da indústria se reduzem persistentemente, como proporção do emprego total e do PIB, respectivamente.

Uma importante discussão é se tal processo ocorre de forma natural ou de forma precoce, que pode ser observado através da relação entre os empregos gerados na economia e a difusão tecnológica. Nos países mais desenvolvidos, a predominância de produtos intensivos em tecnologia reduz o nível de empregos em determinados setores, mas com uma capacidade contínua de adicionar valor ao produto.

Desse modo, existem fatores internos e externos que explicam a causa da desindustrialização e seus rebatimentos da dinâmica da economia. De acordo com Oreiro e Feijó (2010): “Os fatores internos seriam basicamente dois, a saber: uma mudança na relação entre a elasticidade renda da demanda por produtos manufaturados e serviços e o crescimento mais rápido da produtividade na indústria do que no setor de serviços”.

Sendo assim, há nas economias mais ricas uma tendência "natural" de perda relativa do setor industrial em detrimento do crescimento do setor de serviços. Desta forma, o processo de desindustrialização ocorre sem maiores danos à sociedade em relação à geração de emprego, renda e produto. Segundo Clarck (1957): 
As mudanças nos níveis de elasticidade-renda da demanda para produtos industrializados (maior do que um para países com níveis baixos e médios de renda per capita; e ligeiramente menor do que um, para países com níveis elevados de renda per capita) explicam os ganhos relativos da participação do setor de serviços na renda e emprego totais, em detrimento da perda relativa do setor industrial (CLARCK, 1957, p. 9).

Por outro lado, os fatores externos correspondem a inserção da economia nacional no cenário mundial, mediante “[...] o estágio alcançado pelo assim clamado processo de "globalização" (OREIRO e FEIJÓ, 2010). Tais aspectos atuam no sentido de permitir que os diferentes países apresentem diferentes especializações produtivas, uns preponderantemente baseados em produtos manufaturados, e outros em serviços. Neste caso, os fatores externos relacionam-se com o modelo de desenvolvimento particular de cada país, bem como com a relação entre a mão de obra, qualificada ou não, utilizada nos segmentos especializados.

Finalmente, a mudança estrutural pode ser afetada pela "Doença holandesa", que se refere à relação existente entre a exploração de recursos naturais e o encolhimento do setor industrial. A égide do termo está associada aos anos de 1970, período em que a Holanda passou por um declínio da atividade industrial em contrapartida pela descoberta de uma significativa fonte de recurso natural: o gás natural. Com a exploração e a crescente expressividade das exportações do gás, elevou-se o montante de recursos financeiros oriundos das receitas de exportação. Assim, com resultado, suscitou uma valorização em excesso da moeda holandesa da época.

A sobrevalorização da moeda impactou na competitividade dos produtos industriais, incentivando as importações em detrimento da produção doméstica. Em suma, a desindustrialização quando determinada pela "doença holandesa" está relacionada com a redução da competitividade do setor industrial e crescente superávits nos setores não industriais. Como ressaltam Lacerda e Nogueira (2008):

O processo de desindustrialização não significa apenas a substituição da produção nacional já existente por similares importados. Fundamentalmente, este processo restringe a expansão da capacidade produtiva nacional, seja pela transferência de recursos para indústrias de baixa intensidade tecnológica, seja pela diferença entre o efetivo crescimento da demanda por manufaturados nos mercados interno e externo, e o seu verdadeiro potencial (LACERDA; NOGUEIRA, 2008, p. 3)

Reside nesse ponto a problemática da precocidade da desindustrialização em alguns países. A ocorrência da "doença holandesa" é concomitante com um nível de renda per capita baixo e um setor industrial que não atingiu estágios suficientes de produtividade e competitividade compatíveis com os alcançados nos países desenvolvidos. 
O expediente até então apresentado, necessariamente, está indissociável da discussão do padrão de desenvolvimento brasileiro em face ao processo de desindustrialização e sua natureza precoce, bem como a possível ocorrência da doença holandesa (FILGUEIRAS, 2012). Sendo assim, o próximo abordará os delineamentos metodológicos que serão utilizados com vistas a alcançar o objetivo proposto no presente artigo.

\section{Procedimentos metodológicos}

A seção que agora se inicia, indubitavelmente, pretende apresentar os contornos relacionados à metodologia do estudo, em que os limites da pesquisa devem ser explicitados nas tipologias adotadas, perfil e natureza dos dados, instrumentos de mensuração para aferição dos resultados, cuja preocupação central é demarcar o desenho aqui perseguido.

Indicadores de análise regional

Os primeiros pesquisadores a aplicar e sistematizar os indicadores de análise regional no Brasil foram Lodder (1971) e Haddad (1989). Ambos são referências importantes da aplicação empírica desse instrumental ao caso brasileiro. Entretanto, outros estudiosos regionais fazem referência a esse instrumental analítico, como: Monasterio (2011), Alves et al. (2006), Ferrera de Lima et al. (2006), Piffer (1997; 2009), Piacenti e Ferrera de Lima (2012), entre outros.

Para a estimativa dos indicadores de análise regional procedeu-se à construção da matriz de informações: organizaram-se as informações em uma matriz que relacionou a distribuição setorial-espacial da variável base. Com as matrizes construídas, o cálculo de diferentes tipos de medidas permitiu "descrever padrões de comportamento dos setores produtivos no espaço econômico, assim como padrões diferenciais de estruturas produtivas entre as várias regiões" (HADDAD, 1989, p. 227).

\section{A matriz de Informações Espaciais}

As informações foram organizadas em uma matriz, na qual cada linha mostra a distribuição total do emprego formal de uma dada atividade industrial entre as diferentes 
regiões brasileiras, e cada coluna mostra como o emprego formal total de uma dada região se distribui entre as diferentes atividades industriais.

Para a construção da matriz espacial define-se:

$E_{i j}=$ emprego formal na atividade industrial $i$ da região $j$;

$E_{. j}=\sum_{i} E_{i j}=$ emprego formal em todas as atividades industriais da região $j ;$

$E_{i .}=\sum_{j} E_{i j}=$ emprego formal na atividade industrial $i$ de todas as regiões;

$E . .=\sum_{i} \sum_{j} E_{i j}=$ emprego formal em todas as atividades industriais de todas as regiões.

Assim, pode-se apresentar a matriz de informação da seguinte forma:

Figura 1 - Matriz de informação.

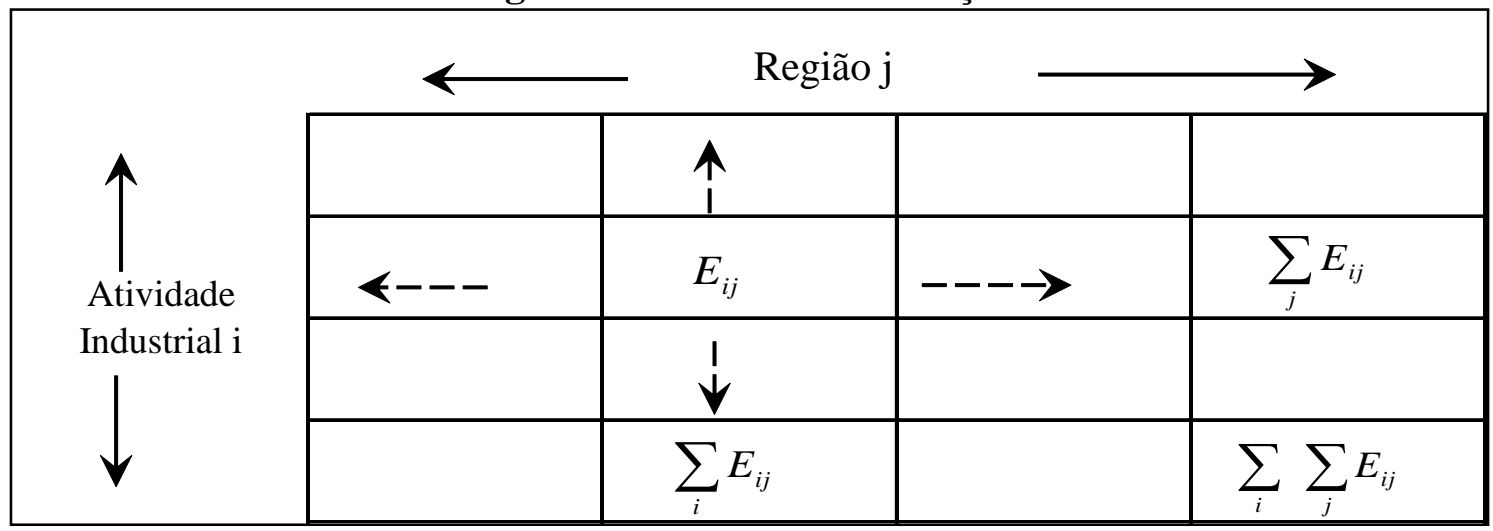

Fonte: Adaptado de Haddad (1989, p. 226).

A partir da matriz espacial, são derivadas outras duas que mostram, em termos percentuais, a distribuição do emprego em cada região por atividade industrial, e a distribuição do emprego de cada atividade industrial entre as regiões brasileiras:

$$
\begin{gathered}
i^{e} j=\frac{E_{i j}}{\sum_{i} E i j} \\
j^{e} i=\frac{E_{i j}}{\sum_{j} E_{i j}}
\end{gathered}
$$

sendo: $\sum_{i} i^{e} j=1,00 ; \sum_{j} j^{e} i=1,00 ; i^{e} .=\sum_{j} i^{e} j ;$ e $j^{e} .=\sum_{i} j^{e} i$.

As medidas regionais concentram-se na análise da estrutura produtiva das atividades industriais de cada região, identificando a distribuição do emprego formal e a especialização das economias regionais, no período de 1995 a 2015. 
Medidas de localização

As medidas de localização são medidas de natureza setorial e se preocupam com a localização das atividades industriais entre as regiões brasileiras. O principal objetivo foi identificar padrões de concentração ou dispersão espacial do emprego formal, bem como as mudanças na estrutura da economia, nos anos de 1995 a 2015.

\section{Quociente Locacional}

O Quociente Locacional (QL) da atividade industrial $i$ na região $j$ foi definido como:

$$
Q L_{i j}=\frac{E_{i j} / E_{i .}}{E_{. j} / E . .}
$$

O QL comparou a participação percentual de uma região, em uma atividade industrial particular, com a participação percentual da mesma região, no total do emprego formal das atividades industriais do Brasil. Se o valor do quociente for maior do que 1 (um), isto significa que a região foi, relativamente, mais importante no contexto nacional, em termos da atividade industrial particular, do que em termos gerais de todos as atividades industriais analisadas.

\section{Configuração da indústria brasileira: concentração e assimetrias regionais}

A concentração geográfica da atividade industrial é um problema historicamente persistente na discussão da economia brasileira e que ressalta as disparidades regionais do país. A organização territorial do setor culminou com uma configuração espacialmente concentrada, principalmente, nas regiões Sudeste e Sul do Brasil.

A análise do limiar do processo de industrialização brasileira, pós década de 1930, já indicava uma elevada concentração espacial devido ao maior dinamismo do Sudeste, motivado por economias de aglomeração advindas de um mercado interno mais consolidado, pela flexibilidade do capital cafeeiro e pela adoção do processo de substituição de importações (SOBRINHO; AZZONI, 2014).

Prebisch (2000) sustenta que o Processo de Substituição de Importações (PSI) tem como traço marcante a relevância de haver proteção nacional diante de itens importados para estimular o crescimento do mercado interno, na tentativa de inverter a causalidade do 
crescimento voltado dessa forma para dentro. Esse aspecto, por sua vez, delimita que uma nação periférica alcançaria o desenvolvimento elevando o nível de produção industrial, aumentando a elasticidade renda das exportações.

A análise histórica do valor adicionado é relevante para a compreensão da contribuição de cada segmento para o PIB do país. Esses dados estruturais, no caso brasileiro, permitem constatar o crescimento do setor terciário, em detrimento da queda dos demais setores produtivos (Gráfico 1). A agropecuária, em 1947, teve uma participação superior a indústria de transformação, embora tenha sido menor que a indústria total. Os contínuos planos de desenvolvimento e a implementação da política de substituição conduziram um salto importante para a industrialização brasileira, principalmente na década de 1950.

A partir de 1955, verifica-se a progressiva redução da atividade agropecuária, bem como uma acentuação do valor adicionado da indústria, enquanto que o setor terciário permanecia com uma participação em torno de 50\%. O ponto de inflexão ocorre em 1985, quando a indústria de transformação atinge seu ponto máximo (35,9\%), em detrimento do crescimento do setor terciário. Desta forma, é possível notar uma mudança estrutural da economia brasileira, que combina um setor de serviços persistentemente mais representativo, com uma tendência de queda do peso da indústria e da agropecuária no PIB nacional.

Gráfico 1 - Valor adicionado das atividades produtivas no PIB brasileiro.

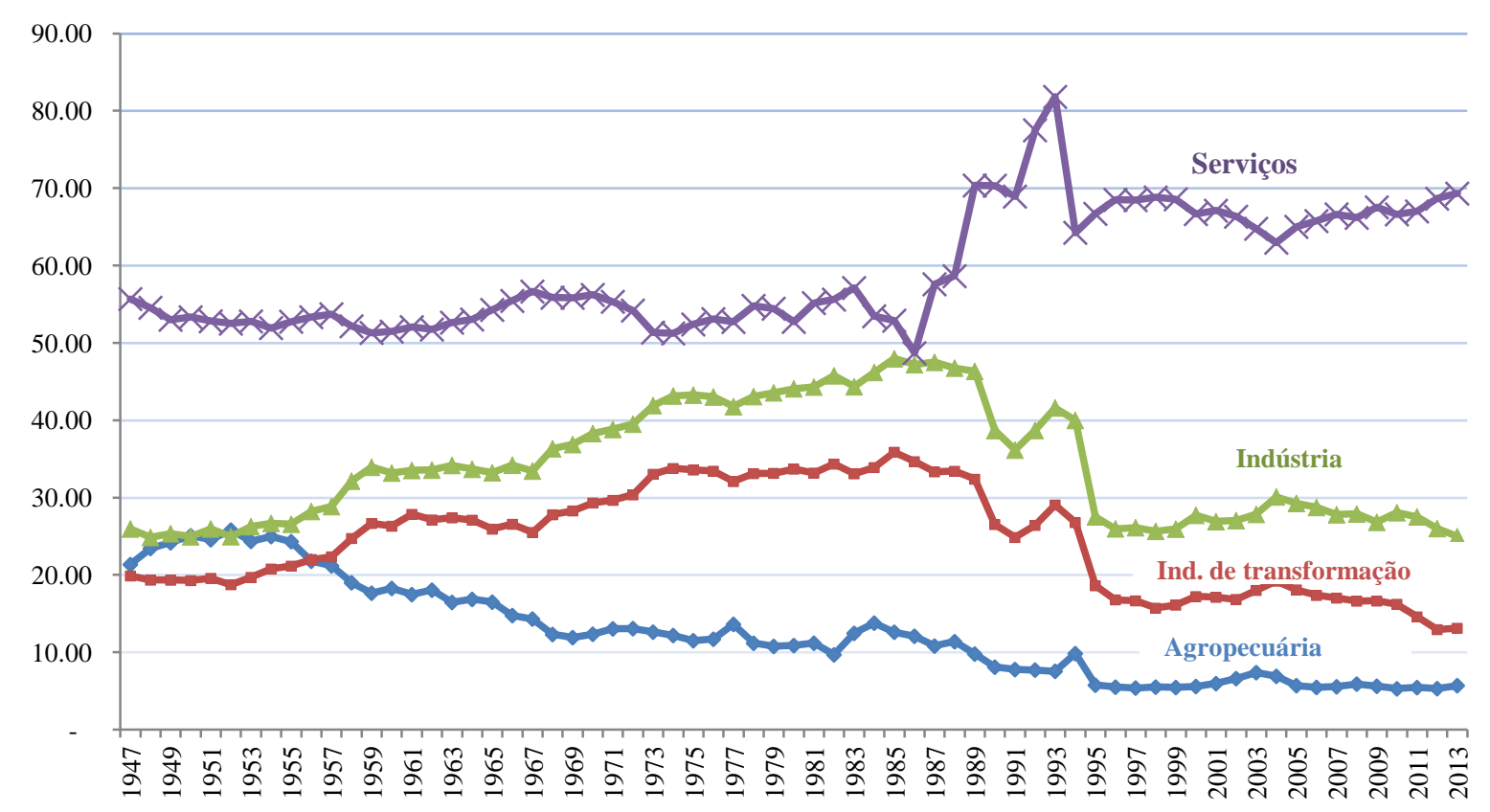

Fonte: Elaboração própria da autora a partir dos dados do IPEADATA (2017).

Sampaio (2017) ressalta a emergência de três momentos na trajetória do decrescimento do setor industrial brasileiro. O primeiro compreende o pós-1985 com a crise doi.org/10.48075/geoq.v14i1.19611 
fiscal e financeira, o segundo pós-1994 com o Plano Real e, finalmente, o pós-2008 com a crise internacional. Filgueiras (2012) mostra que, diferentemente da crise de 1929 que atuou na consolidação da industrialização brasileira, a crise atual reverte o padrão de desenvolvimento de forma regressiva ao acentuar a importância dos setores primários na dinâmica da economia.

Desta forma, a redução do valor adicionado da indústria corrobora o processo de desindustrialização e suscita uma série de questões que envolvem a perda do dinamismo econômico, bem como uma regressão na inserção da economia nacional. Além disso, o autor sinaliza também a emergência de barreiras à diversificação industrial e incremento a vulnerabilidade externa (FILGUEIRAS, 2012).

De acordo com os dados das exportações brasileiras, a participação percentual dos produtos básicos apresentou uma tendência crescente no pós-2000 (Gráfico 2). Em 1995, o setor representava $22,61 \%$ das exportações totais e atingiu 45,6\%, em 2015. Por outro lado, notou-se a perda da importância dos produtos manufaturados e semimanufaturados, sinalizando um processo de substituição da pauta exportadora brasileira e uma nova inserção do Brasil na divisão internacional do trabalho.

Gráfico 2 - Exportações brasileiras por fator agregado, 1995 e 2015.

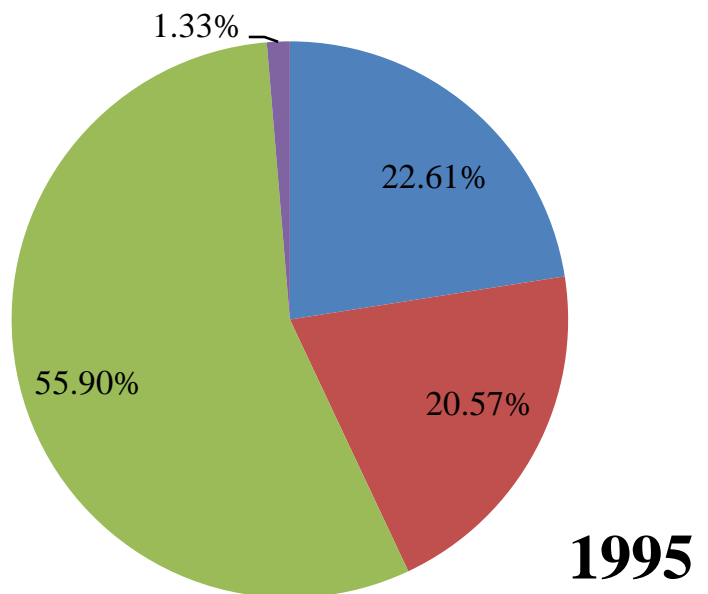

Básicos

Manufaturados
- Semimanufaturados - Operações Especiais



2015

Básicos

Manufaturados

- Semimanufaturados

- Operações Especiais

Fonte: MDIC/SECEX.

Neste contexto, há indícios de uma possível “doença holandesa”, pois o crescimento das exportações de produtos básicos está pautado na expansão da demanda mundial por commodities, a partir dos anos 2000, tendo efeito direto no valor exportado e, consequentemente, numa maior entrada de divisas no mercado brasileiro que contribui para alta valorização da moeda nacional. 
Em 2015, o principal produto básico exportado foi a soja, que representou $11 \%$ das exportações totais, seguida dos minérios de ferro e seus concentrados $(7,4 \%)$ e de óleos brutos de petróleo $(6,2 \%)$. Com relação aos produtos manufaturados, as maiores proporções foram de aviões $(2,1 \%)$, de automóveis de passageiros $(1,8 \%)$ e óxidos e hidróxidos de alumínio $(1,4 \%)$.

As exportações dos produtos manufaturados reduziram sua participação em mais de 17 pontos percentuais, entre 1995 a 2015. Tal como defendido por Teixeira e Pinto (2012), o cenário atual das exportações sinaliza que o Brasil pode estar passando por um processo de reprimarização da pauta exportadora, na qual os produtos tidos como básicos lideram com o crescimento da sua participação. Além disso, os autores reforçam que esse fenômeno resulta numa "especialização regressiva da estrutura produtiva", a qual foi acompanhada de um desempenho industrial mais tímido.

Os autores supracitados reconhecem também que o cenário internacional é uma variável central para entender o dinamismo das commodities, especialmente durante o governo Lula. Paralelamente, o estudo de Bresser Pereira e Marconi (2008) ressalta que a desindustrialização brasileira é um tipo de "doença holandesa", visto que a política cambial pautada na redução da taxa de câmbio, a expansão da demanda mundial e a elevação dos preços das commodities, contribuíram para incentivar a exportação de produtos primários. De forma geral:

$\mathrm{O}$ avanço dos segmentos industriais produtores de commodities e do agronegócio, durante o governo Lula, teve muito mais a ver com a dinâmica internacional do que com políticas estatais. Isso ficou evidente com a manutenção do regime de política macroeconômica, com juros elevados, que gerou valorização cambial, impactando negativamente nos ganhos dos setores mais do que compensados pelo aumento dos preços internacionais das commodities. (TEIXEIRA; PINTO, 2012, p. 21)

Tanto os dados das exportações, quanto do valor adicionado sinalizam a ocorrência da desindustrialização nacional através da reversão da dinâmica econômica, pautada pela acentuação do setor básico face ao declínio do papel da indústria no crescimento econômico. Diante dessa discussão da desindustrialização brasileira, o próximo tópico abordará a configuração do processo no contexto regional com vistas a analisar os distintos movimentos nas regiões brasileiras. 
Perfil espacial da desindustrialização nas regiões brasileiras

Dentre as principais características do processo de industrialização brasileiro, destacase a intensa concentração da indústria no centro-sul, sendo o estado de São Paulo um espaço de proeminência. O auge da concentração espacial da indústria foi na década de 1970, período que São Paulo participou com $40 \%$ da renda nacional e $58 \%$ da produção industrial (BOTELHO, 2002). A consolidação de São Paulo como polo industrial ocorreu em paralelo com a acentuação das desigualdades regionais, que redefiniram uma divisão regional do trabalho no Brasil.

De acordo com Wanderley (2002), a aceleração da industrialização pesada, no período pós década de 1950, bem como as ações estatais, a exemplo do Plano de Metas, contribuíram ainda mais para a concentração industrial no Sudeste. Entretanto, nos anos 1960 e 1970, ocorreu no Brasil o processo de integração produtiva inter-regional, o qual tinha por objetivo a constituição de um cenário econômico nacional mais homogêneo. Segundo Guimarães Neto (1989), esse processo dispersou as especificidades da reprodução do capital e configurou um padrão necessário para a nova forma de acumulação. Esse processo teve como ponto básico a transferência de capitais das regiões mais industrializadas para as demais.

Embora tenham ocorrido transformações na estrutura produtiva, bem como na espacialidade setorial, o setor industrial brasileiro ainda é marcado por elevadas disparidades regionais. Os dados do número de empregos industriais por regiões, em 2015, corroboram a hipótese de uma divisão desigual da atividade no território nacional e sinalizam uma elevada concentração industrial, visível na Figura 2.

O mapa retrata a acentuada concentração espacial da atividade, tendo no Sudeste o seu maior dinamismo. A região Sudeste concentrou mais de 50\% do emprego industrial, sendo São Paulo o estado com maior representação. O Sul aparece com 25,2\% dos empregos, seguido do Nordeste (14\%); Centro-Oeste $(6,24 \%)$ e Norte $(3,84 \%)$, respectivamente.

Nesse sentido, tais dados reforçam que as assimetrias regionais refletem o cenário de desigualdade do país. Os diferentes aspectos institucionais, políticos e socioeconômicos conduziram a uma estrutura regional diferenciada. Essa espacialidade desigual resultou no surgimento de uma vasta literatura acerca da questão regional, com vistas a compreender a heterogeneidade estrutural das regiões brasileiras.

Em seu estudo, Botelho, Sousa e Avellar (2014) corroboram a tese de desindustrialização brasileira e reforçam a incidência desigual do processo quando se analisa o nível estadual e regional. Com base em indicadores do valor adicionado, emprego, 
produtividade, densidade industrial e inserção externa, as autoras sinalizam que a concentração espacial da indústria no Centro-Sul é uma problemática ainda persistente na economia nacional.

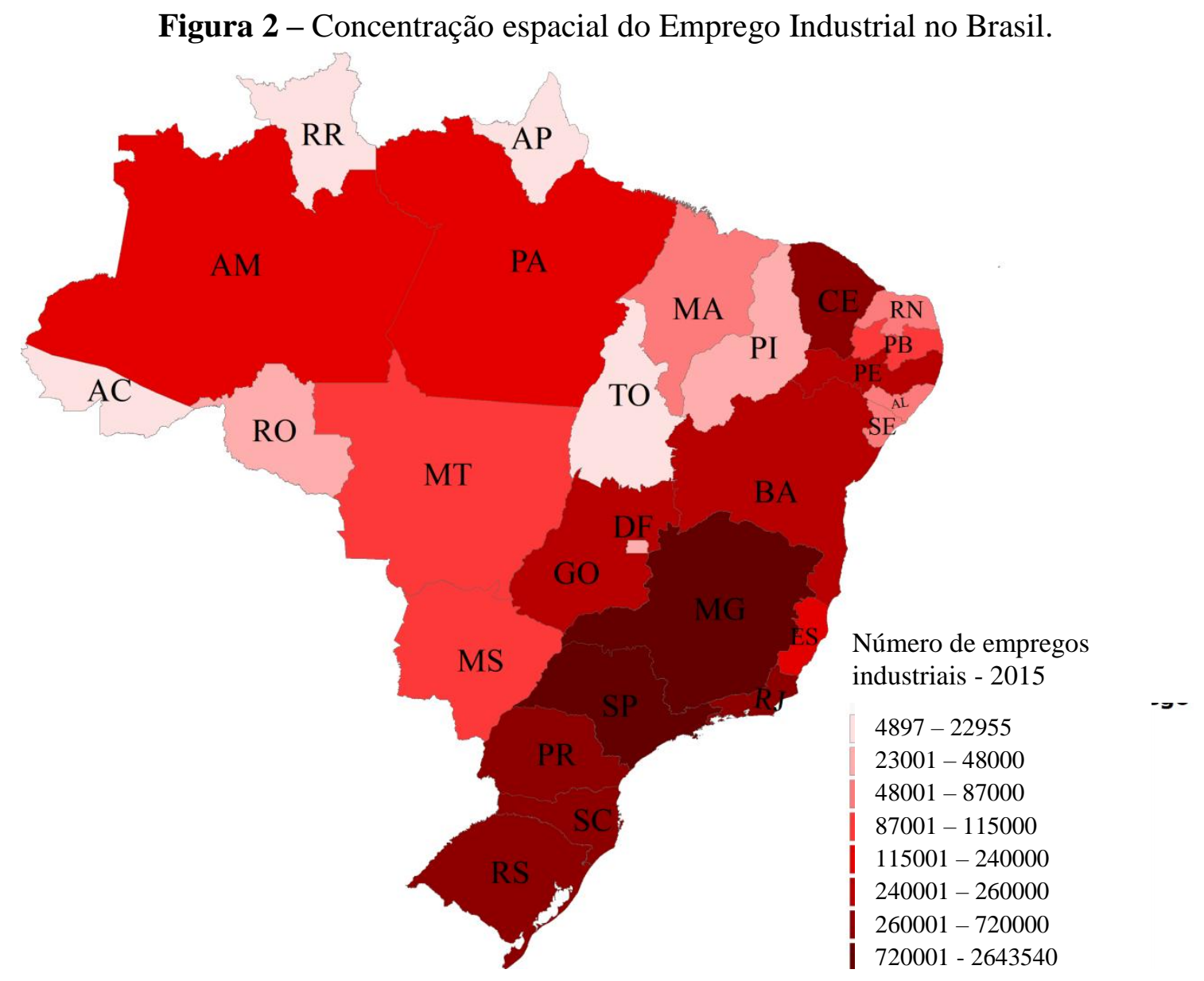

Fonte: Elaboração própria da autora a partir dos dados da RAIS (2017).

Assim, os indícios de desindustrialização brasileira diferem quanto à incidência regional, sinalizando um padrão setorial heterogêneo. O gráfico 3 reitera uma nova divisão regional e uma possível descentralização espacial da indústria, tendo em vista a elevada perda da participação do emprego industrial no Sudeste, em detrimento das demais regiões. No entanto, apesar de uma progressiva redução do peso do emprego industrial no Sudeste, é notória a representativa participação setorial conferida à indústria, que representou mais de $50 \%$ dos empregos totais em 2015. 
Gráfico 3 - Emprego industrial em relação ao emprego total (\%).

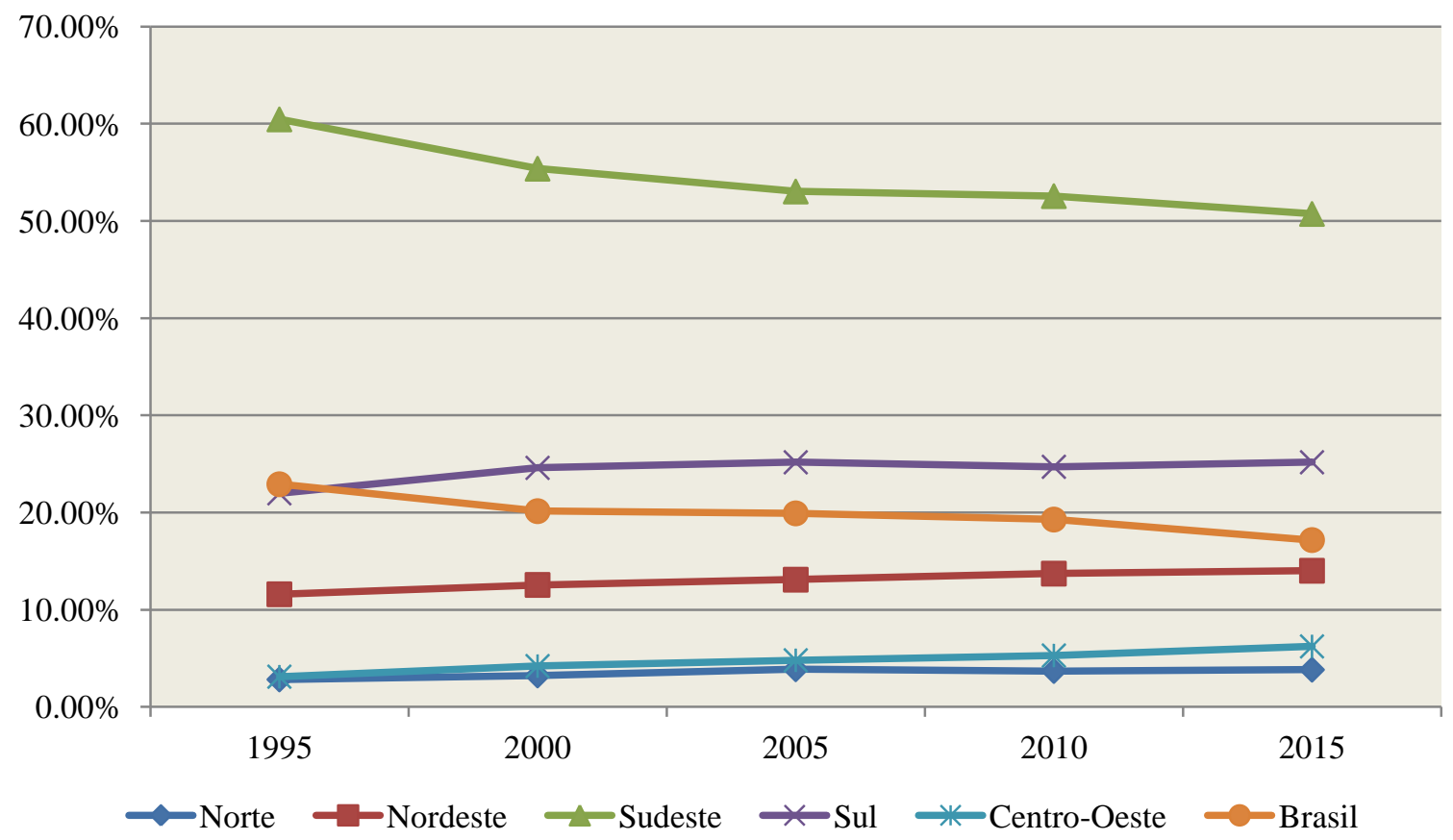

Fonte: Elaboração própria da autora a partir dos dados da RAIS (2017).

Os dados agregados mostram que, entre 1995 a 2015, o emprego industrial no Brasil apresentou uma redução de 5.7 pontos percentuais, no entanto é possível constatar distintos movimentos regionais. O Sudeste apresentou uma redução de mais de 10 pontos de participação, enquanto que as demais regiões aumentaram o peso do emprego industrial em relação ao emprego total.

No entanto, cabe frisar que, apesar das evidências sinalizarem a ocorrência de uma distribuição espacial do emprego industrial, as regiões Norte, Nordeste e Centro-Oeste apresentaram participações menores que a encontrada nacionalmente. Desta forma, parece inegável salientar a necessidade do incentivo e consolidação de um padrão industrial menos concentrado.

A partir da análise do Quociente locacional (QL), no Gráfico 4, pode-se notar a elevada heterogeneidade que caracteriza a indústria nas diferentes regiões brasileiras. Pretende-se, com isto, verificar a dinâmica da indústria de transformação em termos de concentração da atividade em relação ao conjunto do setor industrial para cada região brasileira, ou seja, avalia-se a importância setorial para a região analisada.

No Centro-Oeste, a redução do QL significou a perda da representatividade da indústria de transformação na região, visto que em 2015 apresentou QL<1. Tal fato pode ser explicado mediante crescimento da extrativa mineral, pela produção, principalmente, de ouro 
e ferro. Desta forma, relacionando-se com os dados encontrados no Gráfico 3, o crescimento do emprego industrial na região parece estar associado aos setores menos dinâmicos.

A região Norte apresentou um padrão industrial particularmente diferente das demais regiões. Nos dois períodos de análise, o setor da indústria de transformação foi bastante concentrado, ratificando a importância do mesmo para a economia regional. Em termos relativos, o emprego da atividade cresceu em mais de $100 \%$ durante as duas décadas, se conformando como uma das principais atividades industriais em geração de emprego.

Assim como no Norte, a região Nordeste também conformou uma atividade de indústria de transformação bastante representativa, entretanto com perda ao longo do período de análise. A razão deste motivo parece residir na crescente expressividade do setor de construção civil na economia regional, que se configurou como a segunda região com maior participação do setor no Brasil.

O padrão da estrutura da indústria de transformação na região Sul foi distinto do alcançado nas demais regiões, visto que não apresentou concentração nos anos estudados. Apesar da sua expressividade absoluta, o segmento da indústria de transformação não acompanhou a evolução de setor como de serviços, comércio e da construção civil.

Gráfico 4 - QL do emprego da indústria de transformação no Brasil.

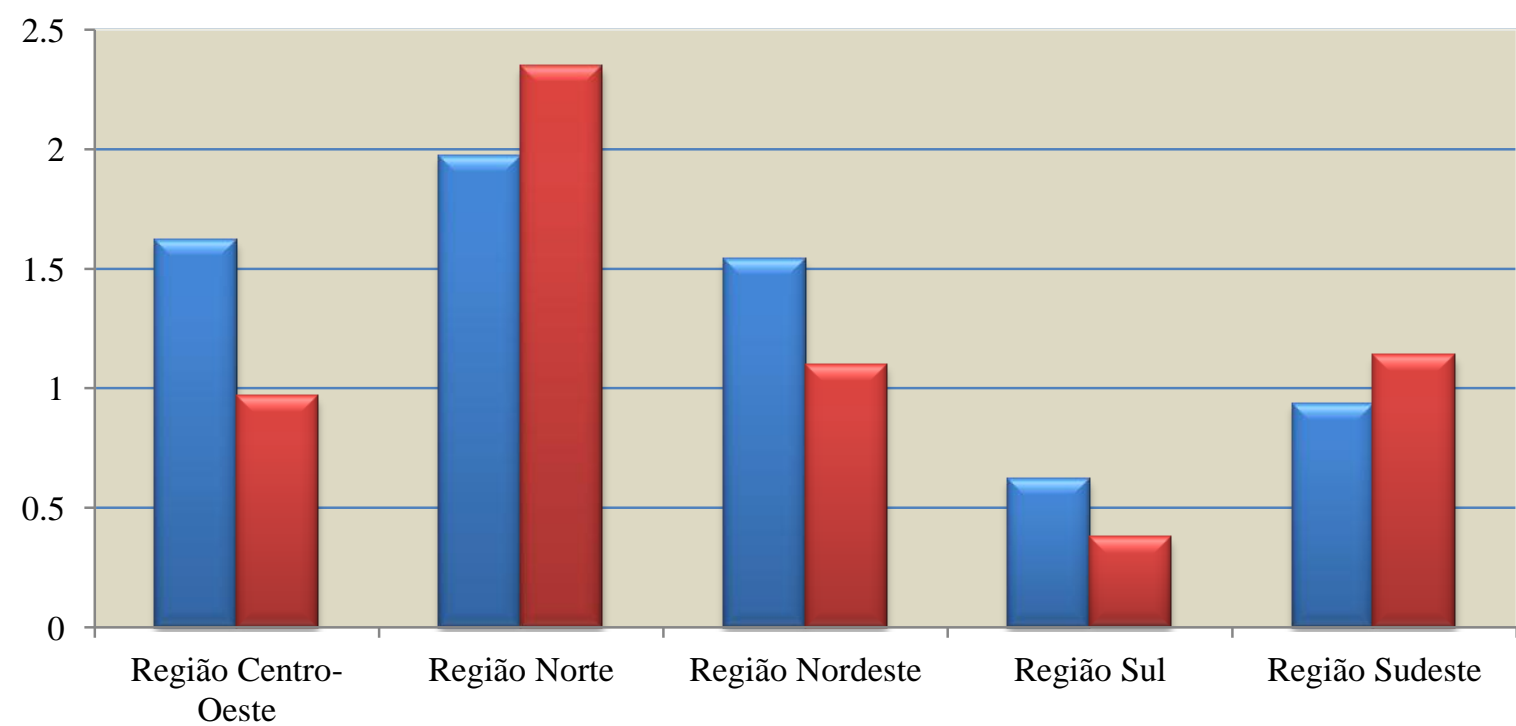

$1995 \square 2015$

Fonte: Elaboração própria da autora a partir dos dados da RAIS (2017).

Por fim, a região Sudeste apresentou uma concentração setorial no ano de 2015, corroborando a maior importância da atividade para o conjunto do setor industrial. Em termos relativos, o segmento da indústria de transformação ultrapassou $16 \%$ dos empregos totais doi.org/10.48075/geoq.v14i1.19611 
gerados, em 2015. Ou seja, apesar da proporção dos empregos industriais ter reduzido em relação aos empregos totais, como visto anteriormente, não foi a indústria de transformação a responsável por esse declínio.

Em síntese, os dados do QL sinalizam a elevada diferenciação industrial, tendo em vista que não há um padrão homogêneo de distribuição espacial entre as regiões brasileiras. Embora existam evidências empíricas do processo de desindustrialização no contexto nacional, o peso do emprego no setor da indústria de transformação não foi reduzido em todas as regiões brasileiras.

\section{Considerações finais}

A persistência histórica das desigualdades regionais no território nacional é uma questão crucial e indissociável do discurso do desenvolvimento brasileiro. Embora o país tenha atravessado uma série de transformações na estrutura produtiva, tais disparidades são visíveis, sejam nos níveis inter-regionais ou intrarregionais. A partir disso, o presente artigo teve por objetivo analisar a ocorrência do processo de desindustrialização em consonância com o padrão espacial da indústria nas regiões brasileiras.

O estudo ressaltou que a configuração histórica da indústria intensificou as disparidades inter-regionais e intrarregionais, desta forma intensifica-se a relevância de políticas industriais destinadas à desconcentração espacial da atividade e criarem internamente fatores favoráveis para sua expansão produtiva nas diferentes regiões.

Os principais resultados apontaram uma perda significativa da indústria no PIB e na geração de empregos, ratificando o processo de desindustrialização no Brasil. No entanto, o recorte espacial por região mostrou diferentes movimentos da dinâmica industrial. Verificouse a redução do peso do emprego industrial no Sudeste, em detrimento do crescimento nas demais regiões. Embora isso possa sinalizar uma descentralização espacial do setor, é visível a elevada concentração no Centro-Sul do país.

Com relação a análise do QL, ao analisar a dinâmica da indústria de transformação comparada ao setor industrial como todo, verifica-se que o Centro-Oeste, o Nordeste e o Sul apresentaram uma redução da importância setorial, embora a atividade tenha permanecido bastante representativa no Nordeste (QL > 1). No Norte e Sudeste, houve incremento da representação da indústria de transformação nas economias regionais. 
Os dados obtidos pela proporção dos empregos industriais em relação ao emprego total em comparação ao QL da indústria de transformação permitem constatar quais regiões apresentaram ganhos de dinamismo, haja visto o caráter primordial da atividade em gerar inovações e maior produtividade.

A redução da proporção do emprego industrial no Sudeste foi contrabalanceada pela maior representação da indústria de transformação. Contudo o crescimento da participação dos empregos industriais nas demais regiões pode ser dividido em um maior peso atribuído a indústria de transformação, como no caso do Norte; e uma perda dessa participação no Centro-Oeste, Nordeste e Sul.

Por fim, os resultados alcançados reiteram a importância de políticas que priorizem uma maior desconcentração produtiva, especialmente na diminuição dos gargalos de infraestrutura existentes nas regiões que impedem uma maior competitividade das áreas mais atrasadas.

\section{Referências}

ALVES, L. R. Indicadores de localização, especialização e estruturação regional. In.: PIACENTI, C. A.; FERRERA DE LIMA, J. (Orgs.) Análise Regional: Metodologias e Indicadores. Curitiba, PR: Camões, 2012.

ALVES, L. R.; FERRERA DE LIMA, J.; RIPPEL, R.; PIACENTI, C. A. O continuum, a localização do emprego e a configuração espacial do oeste do Paraná. Revista de História Econômica e Economia Regional Aplicada. Vol. 1, n. 2. 2006.

BOTELHO, A. A reestruturação produtiva e produção do espaço: O caso da indústria automobilística instalada no Brasil. Revista do Departamento de Geografia, n. 15, p. 55-64, 2002.

BOTELHO, M. dos R. A.; SOUSA, G. F.; AVELLAR, A.P.M. A incidência desigual do processo de desindustrialização nos estados brasileiros. In: XVI Seminário de Diamantina, 2014, Diamantina. Anais do XVI Seminário de Diamantina, 2014.

BRESSER-PEREIRA, L.C \& MARCONI, N. (2008). "Existe doença holandesa no Brasil?". Anais do IV Fórum de Economia de São Paulo, Fundação Getúlio Vargas: São Paulo.

CLARK, Colin (1957). The Conditions of Economic Progress. London: Macmillan.

FERRERA DE LIMA, J.; ALVES, L. R.; PIFFER, M.; PIACENTI, C. A. Análise regional das mesorregiões do Estado do Paraná no final do século XX. Revista Análise Econômica. Ano 24, n. 46. 2006. 
FERRERA DE LIMA, J.; EBERHARDT, P. H. C.; GENTILI, D. C.; HECK, A. L. Mudanças estruturais da ocupação de mão de obra na economia regional do Sudoeste paranaense no início do século XXI. Urbe Revista Brasileira de Gestão Urbana, v. 1, n. 2. 2009.

FILGUEIRAS, L. (2012) A natureza do atual padrão de desenvolvimento brasileiro e o processo de desindustrialização. Relatório de Pesquisa. Centro Celso Furtado, Rio de Janeiro.

GADELHA, C. A. G. (1999) - Desenvolvimento e política industrial: Uma visão Neoschumpeteriana sistêmica e estrutural. Tese de doutorado, Instituto de Economia da UFRJ, Rio de Janeiro.

GUIMARÃES NETO, L. Introdução à formação Econômica do Nordeste. Recife: Massagana, 1989

HADDAD, P. R. Medidas de localização e de especialização. In: HADDAD, P. R. Org. Economia Regional: Teorias e Métodos de Análise. Fortaleza, Banco do Nordeste do Brasil. ETENE, 1989.

LACERDA, A. C. de; NOGUEIRA, R. H. de A. Novas evidências sobre os impactos da valorização cambial na estrutura produtiva brasileira. Seminário PUC/SP, 2008.

LODDER, C. A. Padrões locacionais e desenvolvimento regional. 1971. 187 p. Dissertação (Mestrado em Economia) Escola de Pós-Graduação em Economia (EPGE), do Instituto Brasileiro de Economia, da Fundação Getúlio Vargas.

MONASTERIO, L. Indicadores de Análise Regional e Espacial. In: CRUZ, B. de O.; FURTADO, B. A.; MONASTERIO, L.; RODRIGUES JÚNIOR, W. Org. Economia Regional e Urbana: teorias e métodos com ênfase no Brasil. Brasília: IPEA, 2011.

MINISTÉRIO DO TRABALHO E EMPREGO - MTE. Dados e estatísticas da Relação Anual de Informações e Sociais (RAIS). RAIS Vínculos, 2017. Disponível em: < http://bi.mte.gov.br/bgcaged/rais.php>. Acesso em: 05 jun. 2017.

OREIRO, J.L \& FEIJÓ, C. (2010). "Desindustrialização: conceituação, causas, efeitos e o caso brasileiro". Revista de Economia Política, Vol.30, n.2.

PIACENTI, C. A.; FERRERA DE LIMA, J. (Orgs.) Análise regional: Metodologias e Indicadores. Curitiba, PR: Camões, 2012.

PIFFER, M. A dinâmica do Oeste paranaense: sua inserção na economia regional. Dissertação (Mestrado em Economia). Universidade Federal do Paraná - UFPR, 1997.

PREBISCH, R. (1949) “O Desenvolvimento Econômico da America Latina e Alguns dos seus principais problemas". In: R. Bielschowsky (org.) "Cinquenta Anos de Pensamento da CEPAL-volume 1", Cepal-Record, 2000.

ROWTHORN, R. \& RAMASWAMY, R. (1997). "Deindustrialization: causes and implications". International Monetary Fund, Staff Studies for the Economic Outlook, pp.6177, December. 
ROWTHORN, R. \& RAMASWAMY, R. (1999). "Growth, trade and deindustrialization". International Monetary Fund, IMF Staff Papers, vol. 46, n.1, March.

SAMPAIO, D. P.. Desindustrialização e desenvolvimento regional no Brasil (1985-2015). In: Aristides Monteiro Neto; César Nunes de Castro; Carlos Antonio Brandão. (Org.). Desenvolvimento regional no Brasil: políticas, estratégias e perspectivas. 1ed.Rio de Janeiro: Ipea, 2017, v. , p. 369-396.

SARTI, F.; HIRATUKA, C. Indústria mundial: mudanças e tendências recentes. Campinas: Unicamp. IE, 2010. 34p. (Texto para discussão, n. 186)

TEIXEIRA, R.A. e PINTO, E.C. (2012) A economia política dos governos FHC, Lula e Dilma: dominância financeira, bloco no poder e desenvolvimento econômico. Economia e Sociedade, Campinas, v. 21, Número Especial, p. 909-941, dez. Disponível em http://www.scielo.br/pdf/ecos/v21nspe/v21nspea09.pdf

TREGENNA, F. (2009). “Characterizing deindustrialization: an analysis of changes in manufacturing employment and output internationally". Cambridge Journal of Economics, Vol. 33 (3) p. 433-466.

WANDERLEY, L. Caracterização Industrial e Transformações da Década de 1990: Brasil e Nordeste. In: ROSA, A.; KHAN, A. (orgs.) Nordeste: Reflexões sobre aspectos setoriais e locais de uma economia. Fortaleza: CAEN, 2002 